\title{
A Low-Profile WLAN Antenna with Inductor and Tuning Stub for Broadband Impedance Matching
}

\author{
Woo-Su Kim, ${ }^{1}$ Sunho Choi, ${ }^{2}$ and Gye-Taek Jeong ${ }^{3}$ \\ ${ }^{1}$ Planning and Budget Team, KEIT, 10F KOTECH Building, 305 Teheran-Ro, Gangnam-Gu, Seoul 135-080, Republic of Korea \\ ${ }^{2}$ R\&D Center, GoerTek Korea Co. Ltd, 607 A-dong Digital Empire B/D, 1556 Deogyeong-daero, Yeongtong-gu, Suwon, \\ Gyeonggi-do 443-812, Republic of Korea \\ ${ }^{3}$ RङD Center, WAVE TECH B/D, 15 iljik-ro 94-gil, Seoksu-dong, Anyang, Gyeonggi-do 430-040, Republic of Korea
}

Correspondence should be addressed to Gye-Taek Jeong; gtjeong07@gmail.com

Received 9 January 2014; Accepted 11 March 2014; Published 8 April 2014

Academic Editor: Wenbin Dou

Copyright (C) 2014 Woo-Su Kim et al. This is an open access article distributed under the Creative Commons Attribution License, which permits unrestricted use, distribution, and reproduction in any medium, provided the original work is properly cited.

This paper presents a low-profile multiband antenna suitable for wireless local area networks (WLANs), using a chip inductor and tuning stub for broadband impedance matching. The proposed antenna is compact $\left(12 \times 10 \times 1 \mathrm{~mm}^{3}\right)$ and covers three bands: 2.4-GHz (2.400-2.484 GHz), 5.2-GHz (5.150-5.350 GHz), and 5.8-GHz (5.725-5.825 GHz). The measured 10-dB bandwidths are $12.0 \%(2.28-2.57 \mathrm{GHz})$ in the lower band for 2.4-GHz WLANs and $39.1 \%(4.81-7.15 \mathrm{GHz})$ in the upper band for $5 \mathrm{GHz}-\mathrm{WLANs}$. The measured peak gain of the antenna is between 2.7 and $4.39 \mathrm{dBi}$ and the radiation patterns are omnidirectional.

\section{Introduction}

IEEE $802.11 \mathrm{a} / \mathrm{b} / \mathrm{g}$ standards for wireless local area networks (WLANs) cover the following frequency bands: $2.4 \mathrm{GHz}(2.400-2.484 \mathrm{GHz}), 5.2 \mathrm{GHz}(5.150-5.350 \mathrm{GHz})$, and $5.8 \mathrm{GHz}(5.725-5.825 \mathrm{GHz})$. The use of mobile communication devices for WLAN applications is steadily increasing because multiband WLANs provide easy Internet access and compatibility with other devices and applications. Furthermore, because the rapid spread of smartphones has generated increasing demand for seamless Internet service, WLANs have become a common feature of mobile handsets [1]. While this has led to research into WLAN antennas [2-6], most of the resulting antennas are large or have complicated structural geometries that make them impractical for use in mobile phones.

Mobile phones are still evolving to become lighter and thinner with more diverse functions as technology advances. The space available for the antenna in a mobile phone decreases as the number of internal components increases. This poses a challenge for antenna designers because the antenna efficiency requirements remain unchanged. Early mobile phones had external antennas, which were often helical [7]. However, external antennas have been replaced by internal designs for the sake of aesthetics and durability, based on studies that began in early 2000 [8-10]. Internal antennas for mobile phones are characterized by a low profile and a single substrate; they provide multiband coverage and omnidirectional radiation [4]. Impedance matching is essential in low-profile internal antennas to enhance antenna characteristics [1].

Antenna impedance-matching techniques can be classified into two categories: current impedance matching and lumped element matching. Current impedance matching sometimes results in complexity of design and manufacturing due to the modification of antenna geometry, and losses might be induced by the use of dielectric materials. In lumped element matching, the matching network of inductors and capacitors equalizes the impedance mismatch between the source and antenna load. This approach also results in some degree of loss and complexity [11-13].

This paper proposes a triple-band internal antenna for WLAN applications. The proposed antenna is a modified two-strip monopole antenna with a shunt inductor and tuning stub. To reduce the antenna volume and meet performance requirements, the height was fixed at $1 \mathrm{~mm}$ and the 


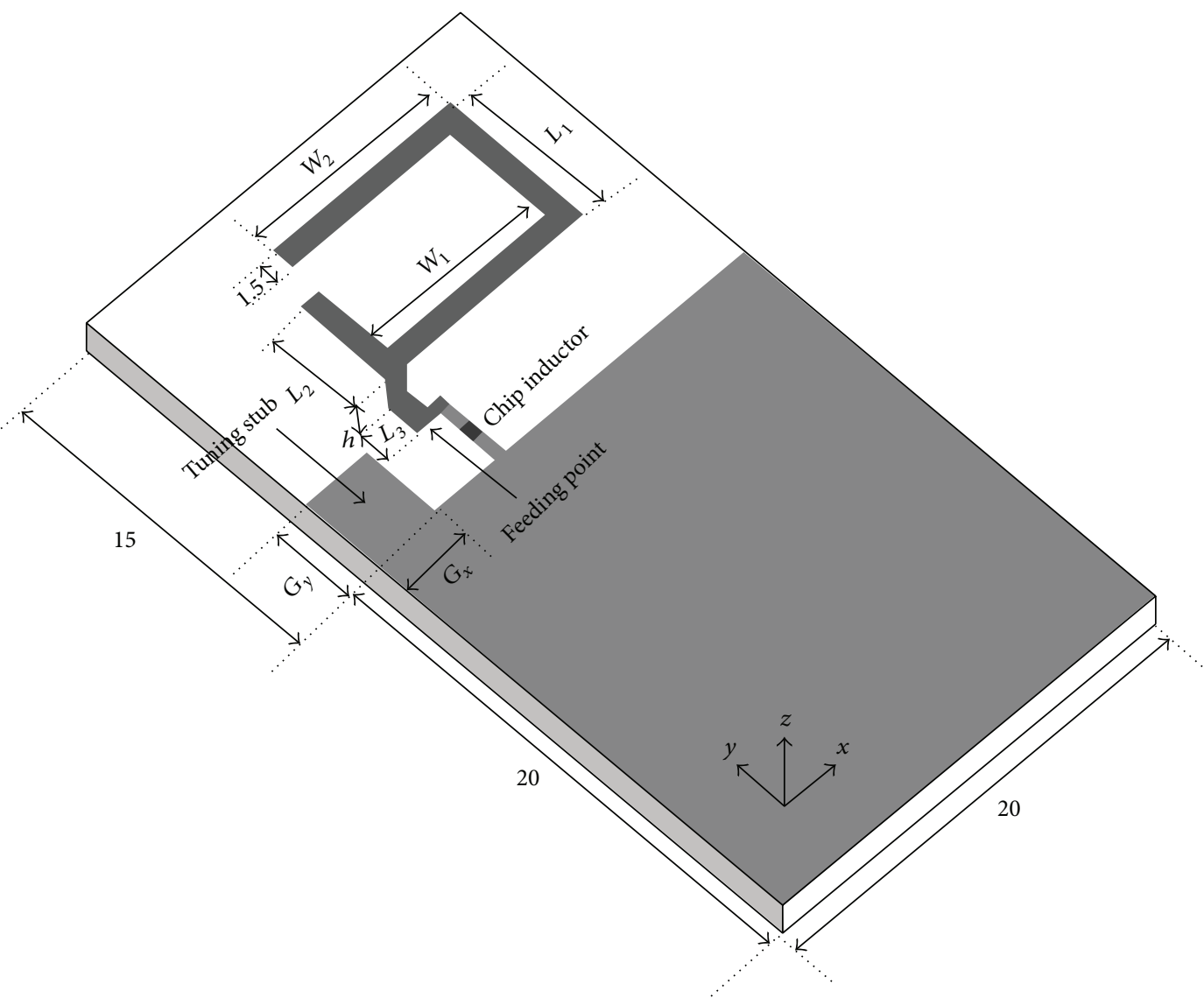

FIgURE 1: Geometry of the proposed WLAN antenna.

strip was folded. A shunt inductor $(L=6.8 \mathrm{nH})$ was added for impedance matching at approximately $2.4 \mathrm{GHz}$ and a tuning stub was included on the ground plane for broadband impedance matching. The capacitive coupling between the tuning stub and antenna tunes the resonance and broadens the impedance bandwidth in the 5-GHz bands. This antenna was designed and analyzed using the CST Microwave Studio software package [14]. Its performance was evaluated by measuring the actual characteristics of a physical prototype. This antenna could be used for triple-band WLAN operations and is much smaller than previous antennas [2-6]. The proposed impedance-matching technique is easily integrated into a PCB without increasing the antenna volume.

\section{Antenna Design}

The structure of the proposed antenna is shown in Figure 1. The antenna is built in an FR4 printed circuit board that is $0.8 \mathrm{~mm}$ thick and has a permittivity of 4.4 ; this material is frequently used in mobile phones due to its low cost. The substrate is $20 \times 35 \mathrm{~mm}$ and the system ground is $20 \times 20 \mathrm{~mm}$. The antenna is a two-strip monopole with a shunt inductor and tuning stub. As shown in the figure, the folded monopole antenna geometry widely used in mobile handsets is used here to obtain dual resonance, omnidirectional radiation, and compact size.
Figure 2 shows the simulated reflection coefficient of a two-strip monopole antenna as a function of height $h$. In this simulation, the parameters were set as follows: $L_{1}=8.0 \mathrm{~mm}$, $L_{2}=4.7 \mathrm{~mm}, L_{3}=2 \mathrm{~mm}, W_{1}=9.0 \mathrm{~mm}$, and $W_{2}=11.7 \mathrm{~mm}$. Figure 2 shows that the higher resonance frequency increased with the height, although the height had little effect on the lower resonance frequency. Conversely, an increase in height improved the impedance matching at the lower resonance but degraded that of the higher band. Therefore, we fixed the height at $1 \mathrm{~mm}$ to include resonances near 2.5 and $5 \mathrm{GHz}$ while maintaining a low physical profile consistent with the latest trend in slim phones. With the height set at $1 \mathrm{~mm}$, the current path length of strip 1 was $31.7 \mathrm{~mm}$, which corresponded approximately to a quarter wavelength of $2.5 \mathrm{GHz}$. The overall length of strip 2 was $7.7 \mathrm{~mm}$, corresponding approximately to a one-eighth wavelength of $5 \mathrm{GHz}$, but this is one-quarter wavelength in relation to $\lambda=c / f \sqrt{\mu \varepsilon}$, where $\mu=1$ and $\varepsilon=4.4$ for the high frequency. However, the antenna must enhance impedance matching and bandwidth for WLAN applications.

Figure 3 shows the simulated reflection coefficients of the antenna for different values of the chip inductor for the same parameters and a height of $1 \mathrm{~mm}$. An inductor parallel to the antenna enhances the impedance matching in the $2.4-\mathrm{GHz}$ band. When the inductance increased, the impedance matching improved, although there was little change in impedance 


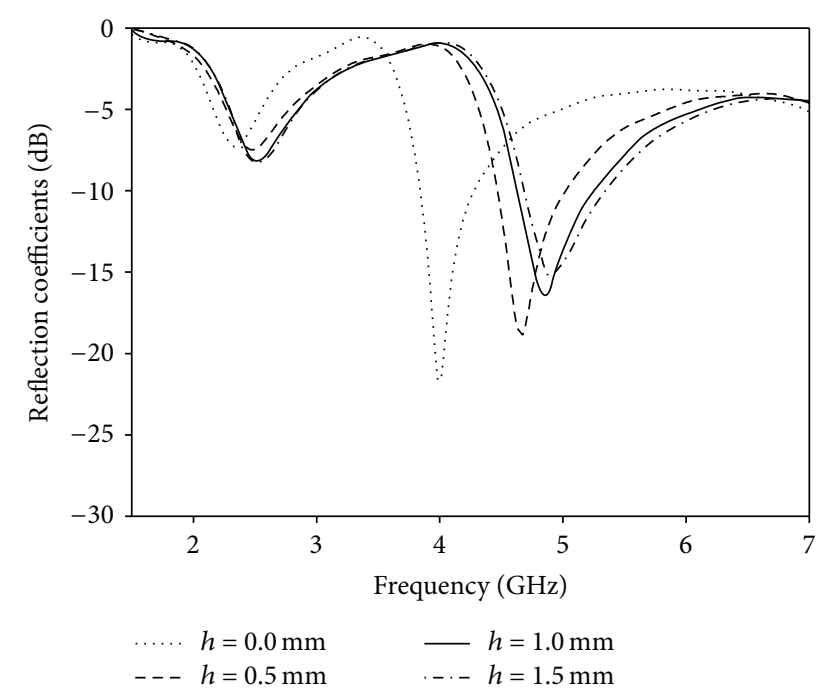

Figure 2: Simulated reflection coefficients of a two-strip monopole antenna as a function of height $h$.

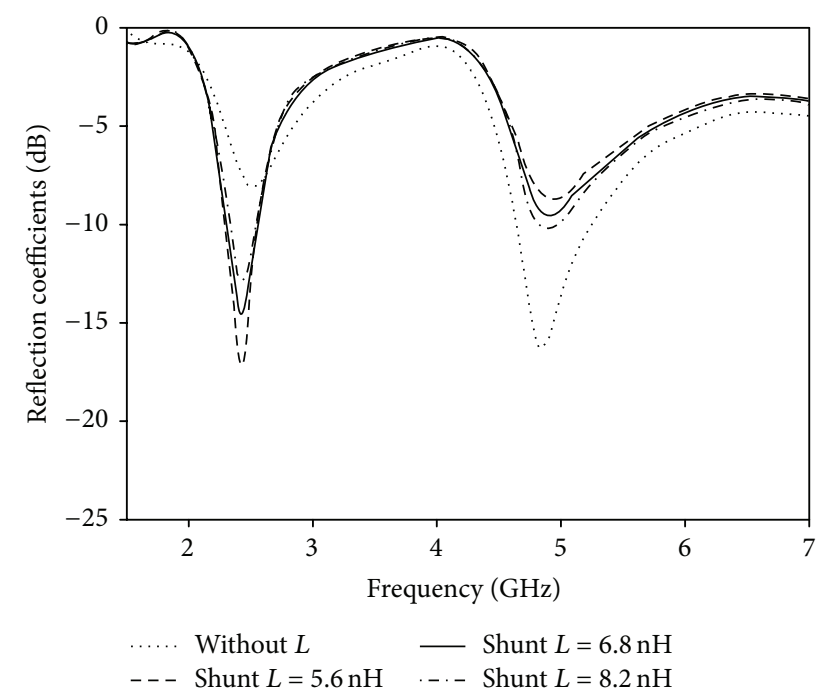

FIGURE 3: Simulated reflection coefficients of the proposed antenna as a function of the chip inductor $(L)$.

matching for the 2.4-GHz band when the value of the inductance was $\leq 6.8 \mathrm{nH}$. When the inductance increased, the impedance matching improved, but the measured antenna gain decreased. Hence, an inductance of $6.8 \mathrm{nH}$ was found to be most appropriate. However, the bandwidth and impedance matching had to be enhanced for the 5.2- and 5.8-GHz bands while maintaining the characteristics of the $2.4-\mathrm{GHz}$ band.

Figure 4 shows the enhancement of the bandwidth and impedance when a tuning stub $\left(G_{x}=3.2 \mathrm{~mm}, G_{y}=3.4 \mathrm{~mm}\right)$ is inserted. Without the tuning stub, the input impedance of the $2.4-\mathrm{GHz}$ band is inside the $2: 1$ voltage standing wave ratio (VSWR) circle, but the input impedance of the 5.2 and $5.8-\mathrm{GHz}$ bands is outside. With the tuning stub, however, all frequency bands required for 5.2- and 5.8-GHz WLAN applications are satisfactory because the impedance locus on

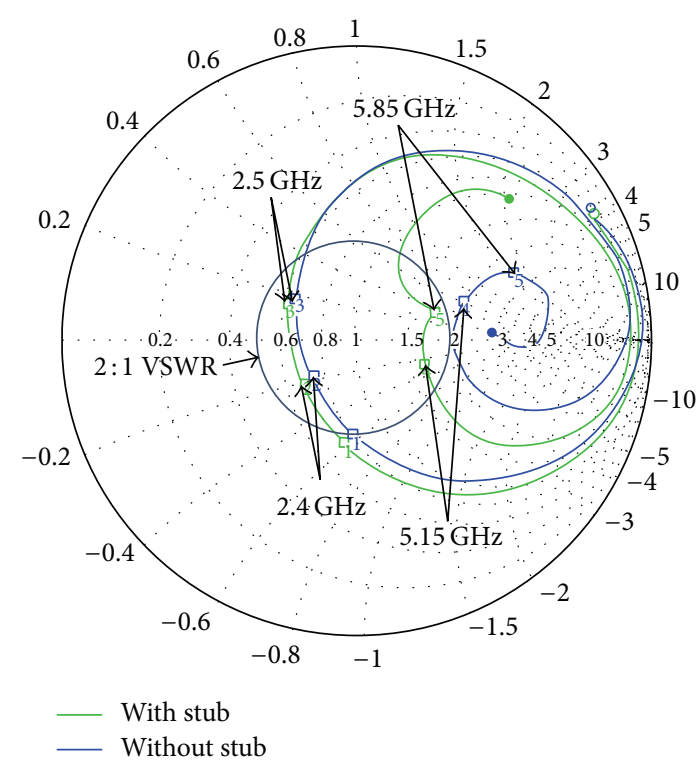

FIGURE 4: Simulated input impedance for the proposed antenna shown on Smith chart with (green) and without (blue) a tuning stub for frequencies $1.50-8.00 \mathrm{GHz}$.

the Smith chart moves inside the circle. Furthermore, the capacitive coupling between the tuning stub and antenna tunes the higher resonance and enhances bandwidth with little change to the lower band. This means that the proposed antenna covers all frequency bands required for 2.4/5.2/5.8$\mathrm{GHz}$ WLAN applications when we choose a tuning stub with appropriate width $G_{x}$ and length $G_{y}$.

Table 1 lists the results of a parameter analysis performed to optimize the tuning stub with the same antenna parameters shown in Figure 3 and an inductance value of $6.8 \mathrm{nH}$. Resonance and the 10- $\mathrm{dB}$ bandwidth of both bands were investigated when the width of tuning stub increased from 2.8 to $3.6 \mathrm{~mm}$ and the height increased from 3.0 to $3.8 \mathrm{~mm}$ in 0.4 $\mathrm{mm}$ increments. Table 1 shows that, without the tuning stub, the 2.4-GHz WLAN band was included, but the 5.2/5.8-GHz band was not. The lower resonance and $10-\mathrm{dB}$ bandwidth were not affected by the size of the tuning stub, but the higher resonance increased with the tuning stub width and length. For a width of $3.0 \mathrm{~mm}$, the $5.8-\mathrm{GHz}$ band was not included. A width of $3.4 \mathrm{~mm}$ resulted in a broad $10-\mathrm{dB}$ bandwidth that included the 5.2/5.8-GHz WLAN band for different tuning stub heights, unlike widths of 3.0 and $3.8 \mathrm{~mm}$. Therefore, the width of the tuning stub was fixed at $3.4 \mathrm{~mm}$. Since a width of $3.4 \mathrm{~mm}$ and length of $3.2 \mathrm{~mm}$ resulted in the maximum 10$\mathrm{dB}$ bandwidth, $3.2 \mathrm{~mm}$ was selected as the most appropriate length.

According to the simulation results, the geometry proposed in this paper can be modeled by the equivalent circuit illustrated in Figure 5. The radiating strip 1, configured with $L_{3}, h, W_{1}, L_{1}$, and $W_{2}$, as indicated in Figure 1, is represented by $L_{\text {strip } 1}, C_{\text {strip } 1}$, and $R_{\text {strip } 1}$. As Figure 3 shows, the shunt chip inductor $L_{\text {chip }}$ is directly related to the resonant frequency of $2.4 \mathrm{GHz}$. Therefore, the radiating strip and the shunt chip inductor can be grouped together, resulting in the admittance 
TABLE 1: Resonant frequency and 10-dB bandwidth for different tuning stubs.

\begin{tabular}{|c|c|c|c|c|c|}
\hline \multicolumn{2}{|c|}{ Tuning stub } & \multicolumn{2}{|c|}{ Lower band } & \multicolumn{2}{|c|}{ Upper band } \\
\hline$G_{x}(\mathrm{~mm})$ & $G_{y}(\mathrm{~mm})$ & $f_{\text {low }}(\mathrm{GHz})$ & $\mathrm{BW}_{\text {low }}(\%)$ & $f_{\text {high }}(\mathrm{GHz})$ & $\mathrm{BW}_{\text {high }}(\%)$ \\
\hline 0 & 0 & 2.42 & 8.2 & 4.90 & 0 \\
\hline \multirow{3}{*}{2.8} & 3.0 & 2.42 & 8.2 & 5.15 & 11.8 \\
\hline & 3.4 & 2.42 & 8.2 & 5.31 & 32.7 \\
\hline & 3.8 & 2.42 & 8.2 & 5.41 & 29.5 \\
\hline \multirow{3}{*}{3.2} & 3.0 & 2.42 & 8.2 & 5.20 & 7.7 \\
\hline & 3.4 & 2.42 & 8.2 & 5.36 & 33.8 \\
\hline & 3.8 & 2.42 & 8.2 & 5.46 & 29.0 \\
\hline \multirow{3}{*}{3.6} & 3.0 & 2.42 & 8.2 & 5.23 & 7.6 \\
\hline & 3.4 & 2.42 & 8.2 & 5.41 & 33.5 \\
\hline & 3.8 & 2.42 & 8.2 & 5.52 & 29.1 \\
\hline
\end{tabular}

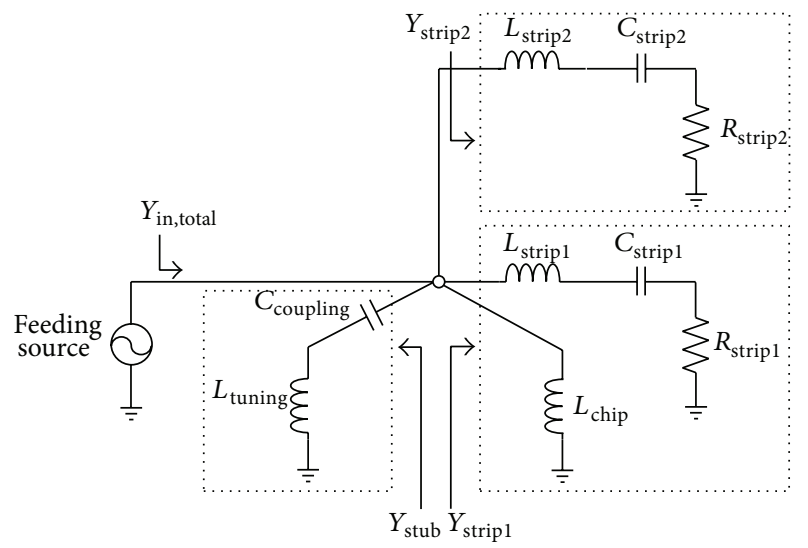

FIGURE 5: The equivalent circuit for the proposed WLAN antenna.

$Y_{\text {strip1 }}$, as shown in Figure 5. Similarly, the radiating strip 2, configured with $L_{3}, h$, and $L_{2}$, is represented by $L_{\text {strip } 2}, C_{\text {strip2 }}$, and $R_{\text {strip2 }}$. The corresponding input admittance is $Y_{\text {strip2 }}$. The tuning stub, represented by $L_{\text {tuning }}$, is connected to the feeding source via the coupling capacitor $C_{\text {coupling. The corresponding }}$ input admittance is $Y_{\text {stub }}$. The approximate value of the admittance for each separate structure can be calculated using the full-wave simulation tool CST Microwave Studio. The resulting values of $Y_{\text {strip } 1}, Y_{\text {strip2 }}$, and $Y_{\text {stub }}$ are $0.0292+j 0.0068$, $0.0057+j 0.0034$, and $0.0078-j 0.0019$ mho, respectively, for $2.4 \mathrm{GHz} ; 0.0004+j 0.0056,0.0148+j 0.0064$, and $0.0176+$ $j 0.0005 \mathrm{mho}$, respectively, for $5.2 \mathrm{GHz}$; and $0.0001+j 0.0038$, $0.0022+j 0.0121$, and $0.0033+j 0.0164$ mho, respectively, for $5.8 \mathrm{GHz}$. The total input impedance $Y_{\text {in,total }}$ can be approximately calculated as $Y_{\text {in,total }} \approx Y_{\text {strip } 1}+Y_{\text {strip } 2}+Y_{\text {stub }}$ by ignoring the redundancy and coupling between equivalent blocks.

\section{Measurement Results}

A prototype antenna was fabricated using the optimized parameters obtained as described in the previous section. The performance of this prototype was characterized in terms of the reflection coefficient, gain, and radiation pattern, which were measured in an anechoic chamber.

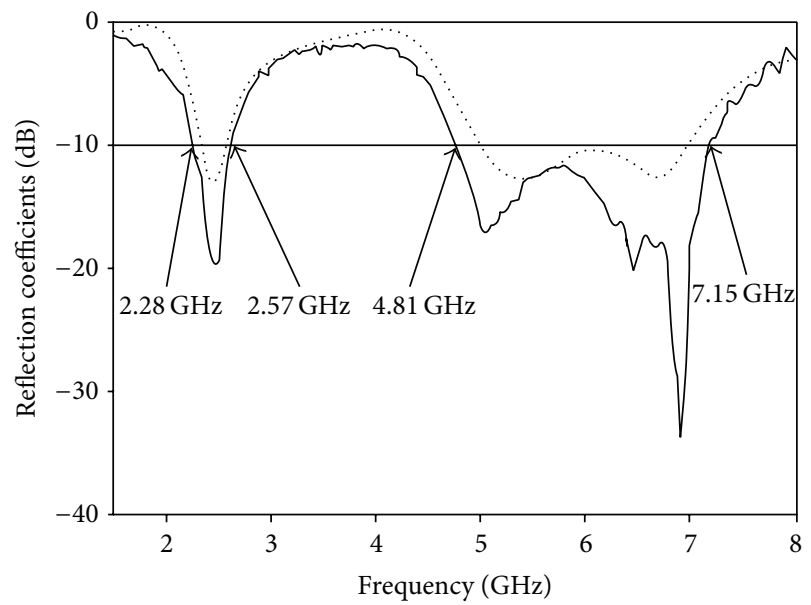

$\begin{array}{rr}\ldots . . . & \text { Simulated } \\ - & \text { Measured }\end{array}$

FIGURE 6: Simulated and measured reflection coefficients of the proposed antenna.

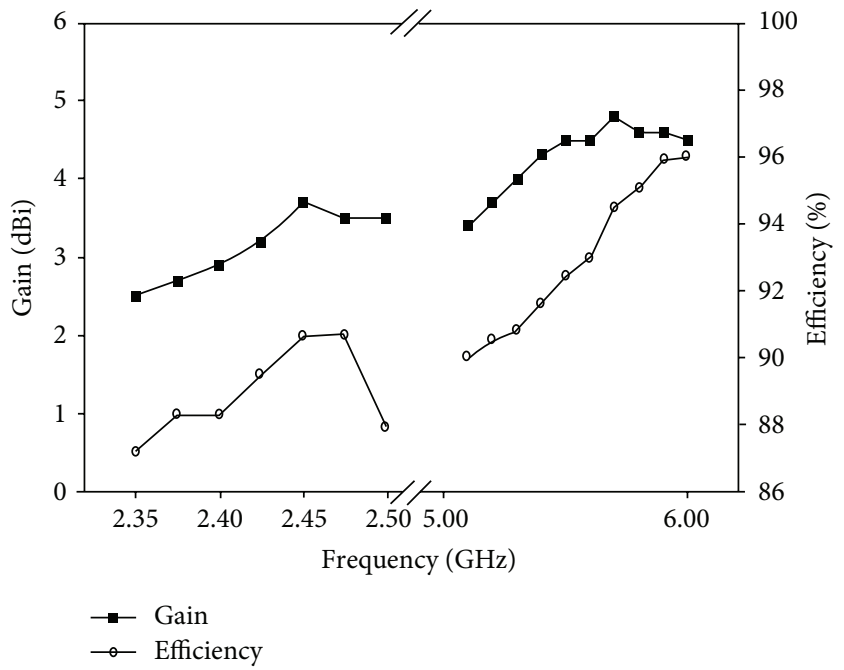

FIGURE 7: Measured radiation efficiency and peak gain of the proposed antenna. 

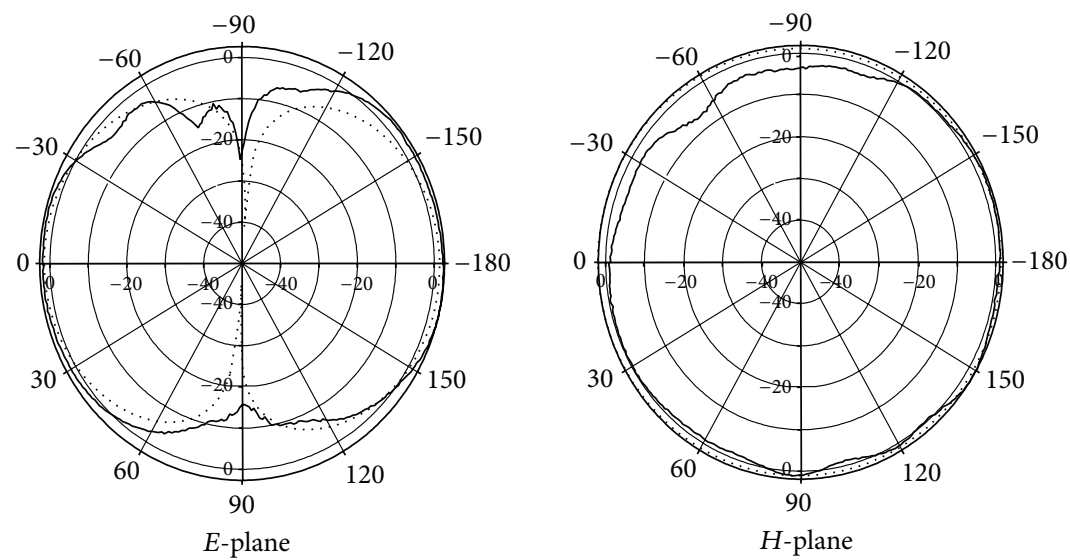

(a) $2.45 \mathrm{GHz}$
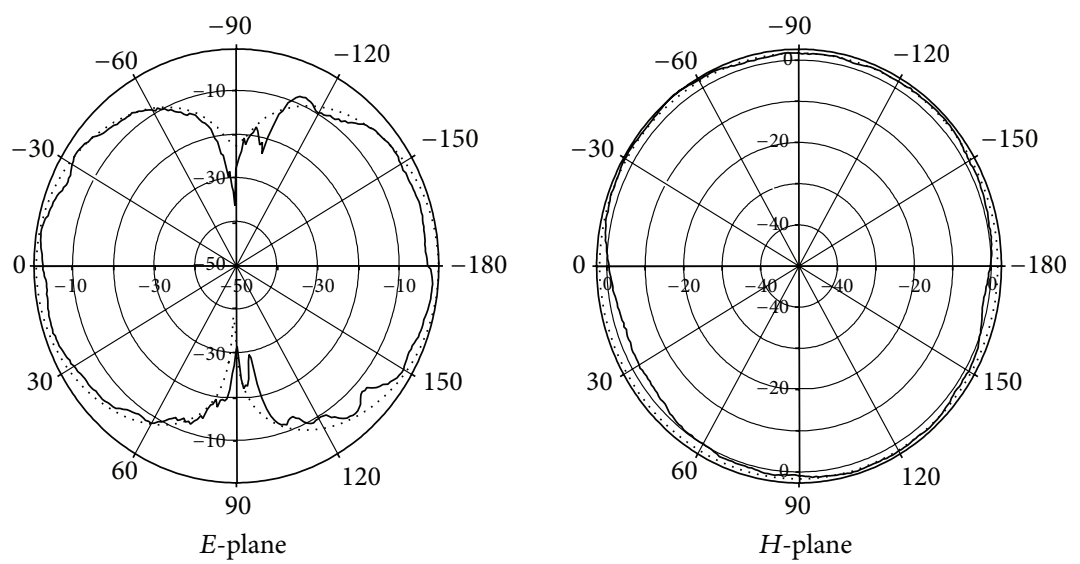

(b) $5.20 \mathrm{GHz}$

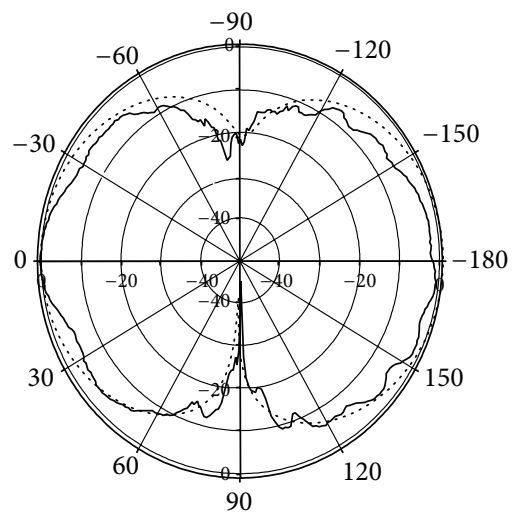

E-plane

..... Simulation

— Measurement

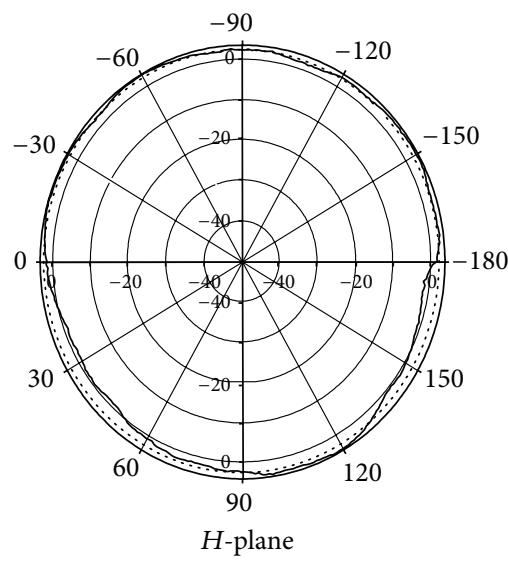

..... Simulation

— Measurement

(c) $5.80 \mathrm{GHz}$

FIGURE 8: Simulated and measured radiation patterns of the proposed antenna.

The compact antennae [2-6] of multiband WLAN services occupy a lot of space and are not easy to integrate with other circuitry. The proposed antenna is smaller than Chiu's antenna [2] and Kim's antenna [3] by $56 \%$ and $12 \%$, respectively. In addition, its bandwidths are wider than those in $[2,3]$ by $6.7 \%$ and $7.0 \%$, respectively, at $2.4 \mathrm{GHz}$ and by $15.0 \%$ and $13.9 \%$, respectively, at $5 \mathrm{GHz}$.

Figure 6 shows that the simulated and measured reflection coefficients of the antenna agreed closely. The 10$\mathrm{dB}$ bandwidth of the prototype was $12.0 \%$ in the lower 
band $(2.28-2.57 \mathrm{GHz})$ and $39.1 \%$ in the higher band (4.81$7.15 \mathrm{GHz}$ ). These results show that broadband impedance matching was achieved and the proposed antenna satisfies the impedance conditions in all frequency bands required for 2.4/5.2/5.8-GHz WLAN applications.

Figure 7 shows the measured peak gain of the prototype antenna. The measured peak gain in the $2.4-\mathrm{GHz}$ band ranges from 2.7 to $3.2 \mathrm{dBi}$. In the $5.2 / 5.8-\mathrm{GHz}$ band, the measured peak gain varies between 2.95 and $4.39 \mathrm{dBi}$. These results are suitable for mobile terminals.

Figure 8 shows the simulated and measured radiation patterns of the prototype antenna at $2.45,5.20$, and $5.80 \mathrm{GHz}$ measured from $0^{\circ}$ to $360^{\circ}$ at $5^{\circ}$-intervals. Good agreement was obtained between the simulated and measured results. These radiation patterns are omnidirectional over all the WLAN operating bands.

\section{Conclusion}

This paper presents a low-profile two-strip monopole antenna with an inductor and tuning stub that can cover the 2.4/5.2/5.8-GHz WLAN frequencies. The narrow bandwidth and poor impedance matching due to the low-profile geometry were enhanced with a tuning stub and shunt inductor. A prototype constructed using optimized parameters had a fractional bandwidth of $12.0 \%$ in the lower band (2.28$2.57 \mathrm{GHz}$ ) and $39.1 \%$ in the higher band $(4.81-7.15 \mathrm{GHz})$. The radiation pattern of the antenna was omnidirectional with a high peak gain of $2.7-4.39 \mathrm{dBi}$. Furthermore, at $12 \times 10 \times$ $1 \mathrm{~mm}$, the overall size of the antenna makes it very promising for compact mobile terminals.

\section{Conflict of Interests}

The authors declare that there is no conflict of interests regarding the publication of this paper.

\section{References}

[1] D. A. Sanchez-Hernandez, Multiband Integrated Antennas for 4G Terminals, Artech House, Boston, Mass, USA, 2008.

[2] C. Y. Chiu, C. H. Chan, and K. M. Luk, "Small dual-band antenna with folded-patch technique," IEEE Antennas and Wireless Propagation Letters, vol. 3, no. 1, pp. 108-110, 2004.

[3] T.-H. Kim and D.-C. Park, "Compact dual-band antenna with double L-slits for WLAN operations," IEEE Antennas and Wireless Propagation Letters, vol. 4, no. 1, pp. 249-252, 2005.

[4] K.-L. Wong and C.-H. Chang, "WLAN chip antenna mountable above the system ground plane of a mobile device," IEEE Transactions on Antennas and Propagation, vol. 53, no. 11, pp. 3496-3499, 2005.

[5] H. Wang and M. Zheng, "An internal triple-band WLAN antenna," IEEE Antennas and Wireless Propagation Letters, vol. 10, pp. 569-572, 2011.

[6] A. G. Alhaddad, R. A. Abd-Alhameed, D. Zhou, C. H. See, P. S. Excell, and S. M. R. Jones, "Folded loop balanced coplanar antenna for WLAN applications," IEEE Transactions on Antennas and Propagation, vol. 60, no. 10, pp. 4916-4920, 2012.
[7] Y. Letestu and A. Sharaiha, "Broadband folded printed quadrifilar helical antenna," IEEE Transactions on Antennas and Propagation, vol. 54, no. 5, pp. 1600-1604, 2006.

[8] M. Ali, R. A. Sadler, and G. J. Hayes, "A uniquely packaged internal inverted-F antenna for bluetooth or wireless LAN application," IEEE Antennas and Wireless Propagation Letters, vol. 1, pp. 5-7, 2002.

[9] K. L. Wong and C. I. Lin, "Internal GSM/DCS antenna backed by a step-shaped ground plane for a PDA phone," IEEE Transactions on Antennas and Propagation, vol. 54, no. 8, pp. 2408-2410, 2006.

[10] V. A. Nguyen, M. T. Dao, Y. T. Lim, and S.-O. Park, "A compact tunable internal antenna for personal communication handsets," IEEE Antennas and Wireless Propagation Letters, vol. 7, pp. 569-572, 2008.

[11] V. Iyer, S. N. Makarov, D. D. Harty, F. Nekoogar, and R. Ludwig, "A lumped circuit for wideband impedance matching of a nonresonant, short dipole or monopole antenna," IEEE Transactions on Antennas and Propagation, vol. 58, no. 1, pp. 18-26, 2010.

[12] D. F. Bowman and E. F. Kuester, "Impedance matching, broadbanding, and baluns," in Antenna Engineering Handbook, J. L. Volakis, Ed., pp. 52-31, McGraw Hill, New York, NY, USA, 4th edition, 2007.

[13] D. M. Pozar, Microwave Engineering, chapter 5, John Wiley \& Sons, New York, NY, USA, 3rd edition, 2005.

[14] CST Microwave Studio (MWS), Version SP2, CST Corporation, Framingham, Mass, USA, 2011. 

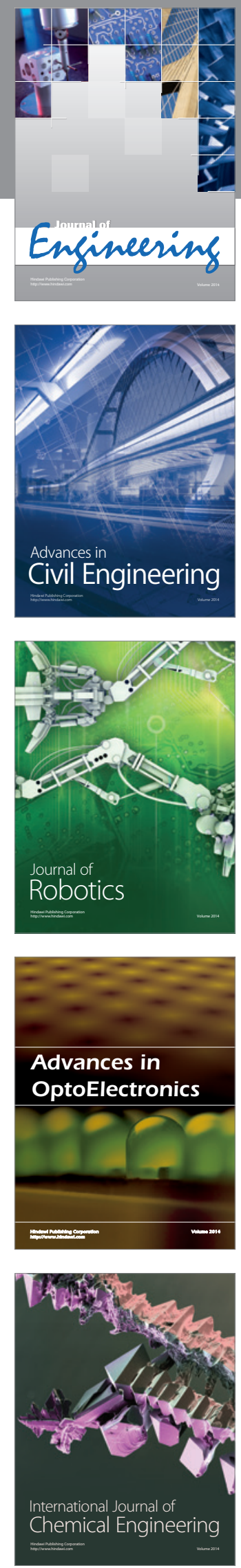

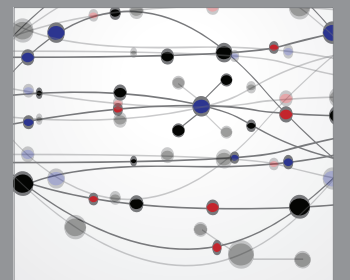

The Scientific World Journal
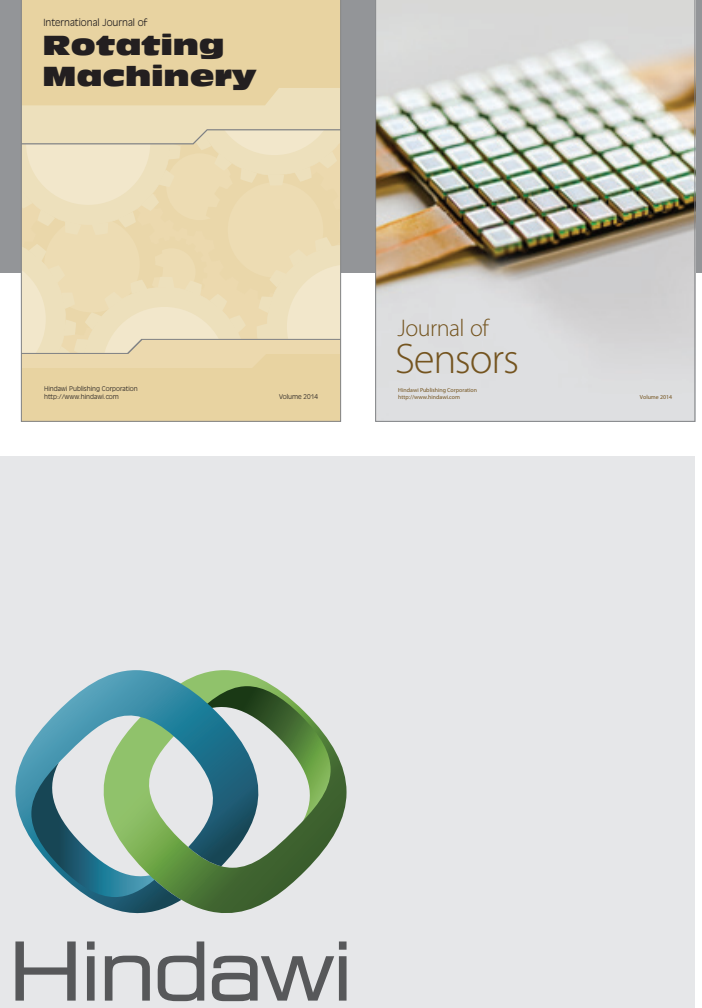

Submit your manuscripts at http://www.hindawi.com
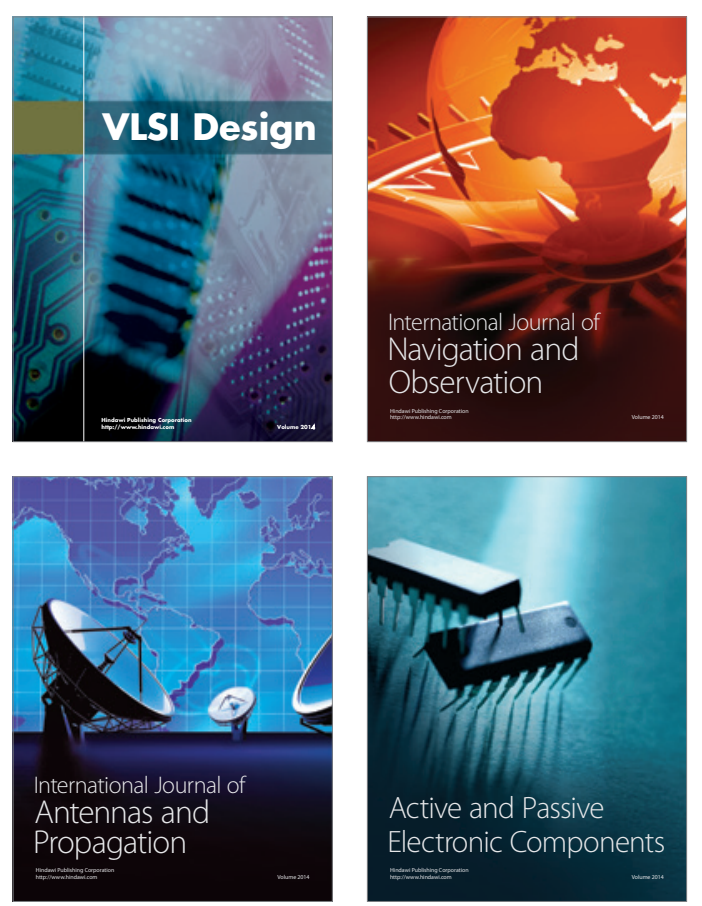
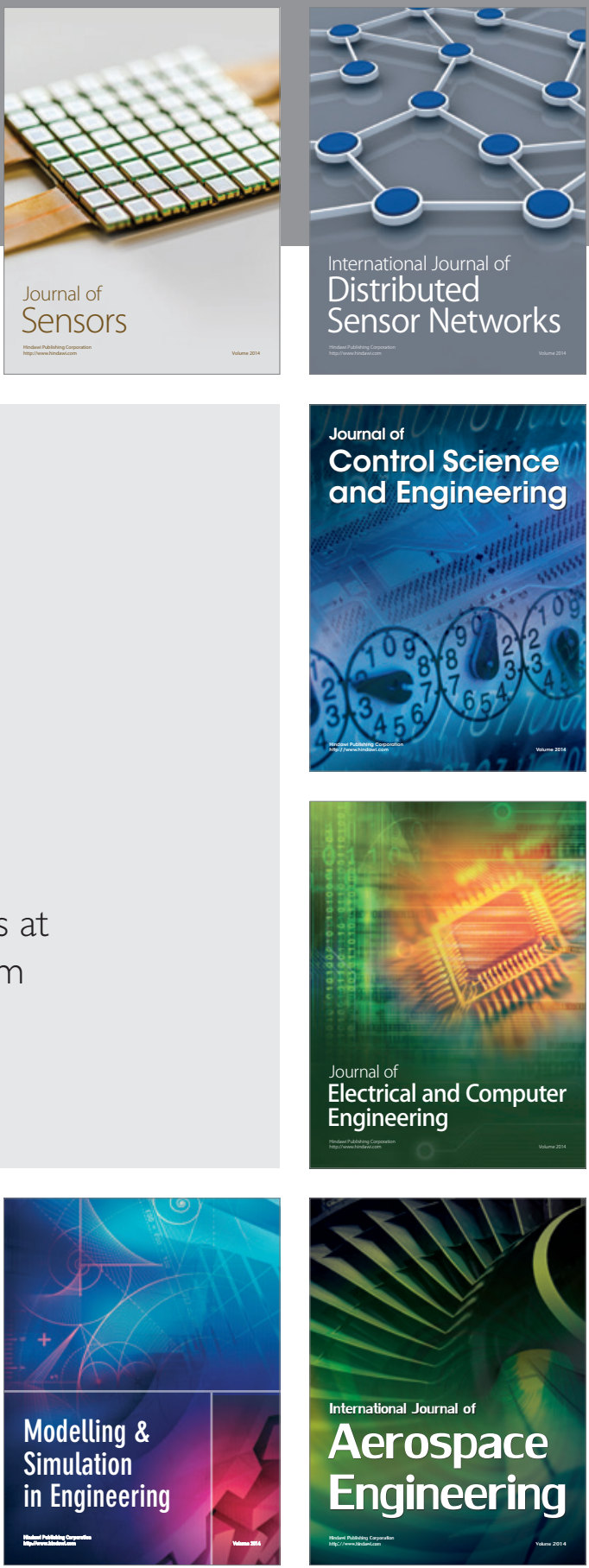

Journal of

Control Science

and Engineering
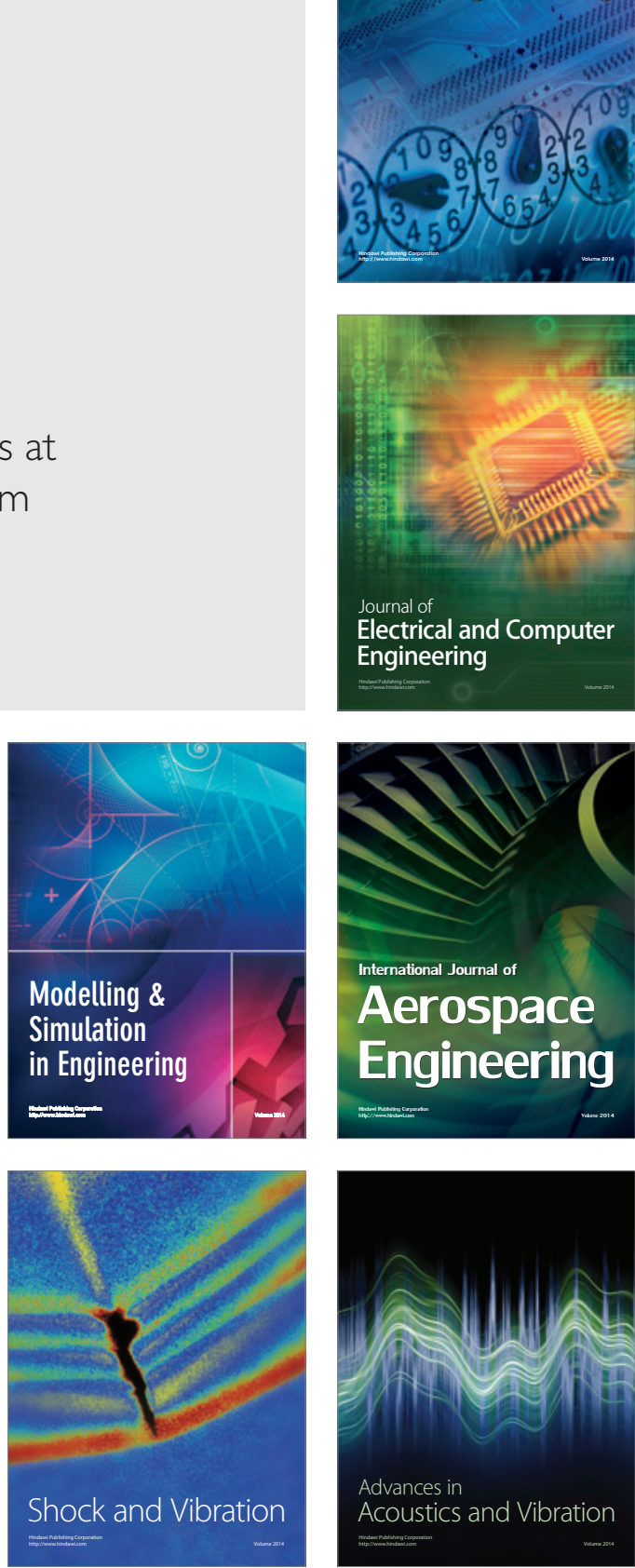